\title{
Methylphenidate Disrupts Social Play Behavior in Adolescent Rats
}

\section{Louk JMJ Vanderschuren*,1,2, Viviana Trezza', Sanne Griffioen-Roose', Olga JG Schiepers², Natascha Van Leeuwen', Taco J De Vries ${ }^{2}$ and Anton NM Schoffelmeer ${ }^{2}$}

'Department of Neuroscience and Pharmacology, Rudolf Magnus Institute of Neuroscience, University Medical Center Utrecht, Utrecht, The Netherlands; '2Department of Anatomy and Neurosciences, Center for Neurogenomics and Cognitive Research, VU University Medical Center, Amsterdam, The Netherlands

\begin{abstract}
Methylphenidate is the first-choice treatment for attention-deficit/hyperactivity disorder (ADHD), but its mechanism of action is incompletely understood. The cognitive effects of methylphenidate have been extensively studied, but little is known about its effects on spontaneous social behavior. During adolescence, rats display a characteristic, highly vigorous form of social behavior, termed social play behavior, which is of critical importance for social and cognitive development. We investigated the neurobehavioral mechanisms by which methylphenidate affects social play behavior in rats. Methylphenidate (0.3-3.0 mg/kg, s.c. or p.o.) abolished social play behavior, without altering general social interest. This effect of methylphenidate did not depend upon the baseline level of social play and was not secondary to changes in locomotion. Furthermore, the play-suppressant effect of methylphenidate was not subject to tolerance or sensitization. Methylphenidate blocked both the initiation to play and the responsivity to play initiation. The effect of methylphenidate was mimicked by the noradrenaline reuptake inhibitor atomoxetine, which is also used for the treatment of ADHD, and was blocked by an $\alpha-2$ adrenoceptor antagonist. In addition, combined administration of subeffective doses of methylphenidate and atomoxetine suppressed social play. However, blockade of $\alpha$-I adrenoceptors, $\beta$-adrenoceptors, or dopamine receptors did not alter the effect of methylphenidate. These data show that methylphenidate selectively blocks the most vigorous part of the behavioral repertoire of adolescent rats through a noradrenergic mechanism. We suggest that the effect of methylphenidate on social play is a reflection of its therapeutic effect in ADHD, that is, improved behavioral inhibition. However, given the importance of social play for development, these findings may also indicate an adverse side effect of methylphenidate.

Neuropsychopharmacology (2008) 33, 2946-2956; doi:I 0.1038/npp.2008. I0; published online 27 February 2008
\end{abstract}

Keywords: social behavior; adolescent; methylphenidate; atomoxetine; $\alpha$-2 adrenoceptor; behavioral inhibition

\section{INTRODUCTION}

Methylphenidate $\left(\right.$ Ritalin ${ }^{\circledR}$, Concerta ${ }^{\circledR}$ ) is the first-choice medication for attention-deficit/hyperactivity disorder (ADHD) (Elia et al, 1999; Kutcher et al, 2004; Fone and Nutt, 2005), a childhood disorder characterized by inattention, hyperactivity, and impulsivity (American Psychiatric Association, 2000; Biederman and Faraone, 2005). Despite the widely recognized efficacy of methylphenidate in the treatment of ADHD, its neurobehavioral mechanism of action is incompletely understood. Methylphenidate blocks the dopamine transporter and the noradrenaline transporter (Ferris and Tang, 1979; Ritz et al, 1987), thus increasing the extracellular concentrations of these catecholamines.

*Correspondence: Dr LJMJ Vanderschuren, Department of Neuroscience and Pharmacology, Rudolf Magnus Institute of Neuroscience, University Medical Center Utrecht, Universiteitsweg 100, 3584 CG Utrecht, The Netherlands, Tel: +31 88 75688।I, Fax: +31 88 7568I55, E-mail: I.j.m.j.vanderschuren@umcutrecht.nl

Received 2 November 2007; revised 2 January 2008; accepted 14 January 2008
Studies in humans have shown that methylphenidate increases impulse control (Tannock et al, 1989; Aron et al, 2003), attention (Solanto et al, 1997; Hawk et al, 2003; Overtoom et al, 2003), and working memory (Mehta et al, 2004) in ADHD patients, as well as in healthy subjects (Elliott et al, 1997; Mehta et al, 2000; Pietras et al, 2003; Volkow et al, 2004). Comparable findings have been obtained in rodents (Arnsten and Dudley, 2005; Berridge et al, 2006; van Gaalen et al, 2006; Bizot et al, 2007; Eagle et al, 2007).

Studies on the effect of methylphenidate on discrete cognitive processes are essential in understanding its mechanism of action. However, the psychopathology of ADHD not only manifests in subjects instructed to engage in a particular task (such as in a classroom setting) but also prominently in spontaneous social interactions, leading to the pattern of unstable relationships, unemployment, and criminal behavior associated with ADHD (American Psychiatric Association, 2000; Biederman and Faraone, 2005). Psychostimulant drugs such as amphetamines are known to disrupt a variety of social behaviors (Schiørring, 
1979; Miczek et al, 1989; Moro et al, 1997). Studies in rodents have shown that methylphenidate disrupts social behavior in adolescent and young adult rats (Beatty et al, 1982; Thor and Holloway, 1983; Arakawa, 1994), but the neurobehavioral background of this effect and its relationship to the therapeutic effects of methylphenidate in ADHD remain elusive. In humans, knowledge on the effects of methylphenidate on social behavior comes from parent and teacher reports, and these studies have for the most part focused on disruptive and aggressive behavior in ADHD (Hinshaw and Lee, 2000; Pelham et al, 2001; Schachter et al, 2001; Connor et al, 2002; Chacko et al, 2005).

Between weaning and sexual maturation (postnatal days 21-60, with a peak between postnatal days 25-40), rats display a great deal of a characteristic, highly vigorous form of social behavior, termed social play behavior (Panksepp et al, 1984; Vanderschuren et al, 1997; Pellis and Pellis, 1998). Social play behavior is thought to subserve social and cognitive development, because social isolation in rats during the 2 weeks in adolescence when social play is most abundant leads to long-lasting behavioral disturbances in the social domain (Hol et al, 1999; Van den Berg et al, 1999a). Thus, because of (1) the limited understanding of the effects of methylphenidate on social behavior in relationship to its therapeutic effects in ADHD and (2) the importance of social play for behavioral development, we investigated the neurobehavioral mechanisms underlying the effect of methylphenidate on social play behavior in adolescent rats, using doses of the drug that are comparable to those used for the treatment of ADHD (Elia et al, 1999; Solanto, 2000; Kuczenski and Segal, 2002; Kutcher et al, 2004).

\section{MATERIALS AND METHODS}

\section{Animals}

Male Wistar rats (Harlan, Horst, The Netherlands, and Charles River, Sulzfeld, Germany) arrived in our animal facility at 21 days of age and were housed in groups of four in $40 \times 26 \times 20 \mathrm{~cm}(l \times w \times h)$ Macrolon cages under controlled conditions (ambient temperature $20-21^{\circ} \mathrm{C}, 60-65 \%$ relative humidity, and $12 / 12 \mathrm{~h}$ light cycle with lights on at 0700 hours). Food and water were available ad libitum. Animals were used only once. Group size was $n=6-16$ in all experiments. All experiments were approved by the Animal Ethics Committees of the VU University Medical Center Amsterdam and the University Medical Center Utrecht and were conducted in agreement with Dutch laws (Wet op de Dierproeven, 1996) and European regulations (Guideline 86/609/EEC).

\section{Social Play Behavior}

All the experiments were performed in a sound attenuated chamber under dim light conditions. The testing arena consisted of a Plexiglas cage measuring $40 \times 40 \times 60 \mathrm{~cm}$ $(l \times w \times h)$ with approximately $2 \mathrm{~cm}$ of wood shavings covering the floor.

Social play was assessed as previously described (Vanderschuren et al, 1995a). At 26-28 days of age, rats were individually habituated to the test cage for $10 \mathrm{~min}$ on 2 days prior to testing. On the test day, the animals were socially isolated for $3.5 \mathrm{~h}$ before testing. This isolation period has been shown to induce a half-maximal increase in the amount of social play behavior (Niesink and Van Ree, 1989). In two experiments, animals were isolated for either 0 or $24 \mathrm{~h}$ before testing, which induces minimal and maximal levels of social play behavior, respectively (Niesink and Van Ree, 1989; Vanderschuren et al, 1995a). At the appropriate time before testing, pairs of animals were treated with drugs or vehicle. In all experiments except for one, both animals of a pair received the same drug treatment. The test consisted of placing two animals into the test cage for $15 \mathrm{~min}$. The animals of each pair did not differ more than $10 \mathrm{~g}$ in body weight and had no previous common social experience. The behavior of the animals was videotaped and analyzed afterward. Coding of the drug solutions ensured that both during experimentation and behavior analysis, the experimenter was unaware of the treatment of the animals.

Behavior was assessed per pair of animals, except in one experiment, in which the behavior of both members of a test pair was scored separately, using the Observer 3.0 software (Noldus Information Technology BV, Wageningen, The Netherlands). In rats, a bout of social play behavior starts with one rat soliciting ('pouncing') another animal, by attempting to nose or rub the nape of its neck. 'Pinning,' that is, one animal lying with its dorsal surface on the floor with the other animal standing over it, occurs if the animal that is solicited upon rotates to its dorsal surface. From this position, the supine animal can initiate another bout of play, by trying to gain access to the other animal's neck. Thus, during social play, pinning, which is considered to be the most obvious posture in social play behavior in rats, is not an end point, but rather functions as a releaser of a prolonged play bout (Poole and Fish, 1975; Panksepp et al, 1984; Pellis and Pellis, 1987; Pellis, 1988). The animal that is pounced upon can also respond by evading, or by turning around to face the other animal. In the latter situation, a brief period of boxing/wrestling may follow, in which the animals try to push each other away. If the solicited animal evades, the other animal may start to chase it, thus making another attempt to launch a play bout (see Vanderschuren et al, 1995b, for a detailed analysis of the temporal structure of social play behavior in rats). The following behaviors were scored per $15 \mathrm{~min}$ : frequency of pinning, frequency of pouncing, and time spent in social exploration, that is, sniffing any part of the body of the test partner, including the anogenital area. In the experiment where both members of a test pair were scored separately, pinning was scored when the subject pinned its partner. In one experiment, locomotor activity of the animals was also scored as follows: a grid, dividing the test arena into 25 equally sized compartments, was projected over the social behavior recordings, and the number of line crossings was counted separately for each animal of a pair.

\section{Drugs and Treatment}

Methylphenidate-HCl (Bufa and Sigma), GBR-12909-diHCl, apomorphine-HCl, cis-(Z)-flupenthixol (Sigma), RX821002$\mathrm{HCl}$, atomoxetine- $\mathrm{HCl}$ (Tocris), and propranolol-HCl (ICI) were dissolved in saline, and prazosin- $\mathrm{HCl}$ (Pfizer) was dissolved in distilled water. Methylphenidate, GBR-12909, 
and apomorphine were administered subcutaneously (s.c.) and atomoxetine was administered i.p. $30 \mathrm{~min}$ before testing. In one experiment, methylphenidate was administered by oral gavage $30 \mathrm{~min}$ before testing. Prazosin, propranolol, RX821002, and cis-(Z)-flupenthixol were administered i.p. $15 \mathrm{~min}$ before methylphenidate or atomoxetine. Drug doses and pretreatment intervals were based on the literature and on pilot experiments. Because of the importance of the neck area in the expression of social play behavior (Pellis and Pellis, 1987; Siviy and Panksepp, 1987), s.c. injections were administered in the flank. Injection volume was always $0.2 \mathrm{ml} / \mathrm{kg}$.

To assess the effect of previous exposure on the effectiveness of methylphenidate to suppress social play behavior, animals were pretreated with methylphenidate $(1.0 \mathrm{mg} / \mathrm{kg}$, s.c.) or saline for 5 consecutive days (postnatal days 26-30). On day 31 , one day after the last pretreatment injection, animals were isolated for $3.5 \mathrm{~h}$. Next, half of both pretreatment groups was treated with methylphenidate ( 0.1 or $1.0 \mathrm{mg} / \mathrm{kg}$, s.c.), and the other half was treated with saline, $30 \mathrm{~min}$ before the test, and tested for social play behavior as described above.

\section{Statistics}

Pinning and pouncing frequencies, time spent in social exploration, and line crossings were expressed as mean \pm SEM. To assess the effects of single or combined treatments on social play behavior, data were analyzed using one-way or two-way analysis of variance, respectively, followed by the Student-Newman-Keuls post hoc tests where appropriate.

\section{RESULTS}

\section{Methylphenidate Specifically Suppresses Social Play Behavior}

Treatment with methylphenidate $(0.3-3.0 \mathrm{mg} / \mathrm{kg}$, s.c.) dosedependently suppressed social play behavior. Pinning (Figure 1a) as well as pouncing (Figure 1b) was nearly absent after treatment with the highest dose of methylphenidate. In contrast, social exploration was not affected by methylphenidate treatment (Figure 1c). We next investigated the effect of lower doses of methylphenidate on social play behavior to exclude the possibility that methylphenidate exerts biphasic effects on social play. At doses of 0.01 and $0.1 \mathrm{mg} / \mathrm{kg}$, methylphenidate did not alter pinning, but consistent with the previous experiment, $1.0 \mathrm{mg} / \mathrm{kg}$ methylphenidate reduced pinning (Figure 1d) as well as pouncing $\left(\mathrm{F}_{3,30}=8.76, \quad p<0.0001\right.$; data not shown $)$. To evaluate whether the effect of methylphenidate depended on the baseline level of social play, we assessed its effect in animals that had been socially isolated for 0 or $24 \mathrm{~h}$ prior to testing. After $0 \mathrm{~h}$ of social isolation, saline-treated rats displayed levels of pinning that were approximately one-third of those isolated for $3.5 \mathrm{~h}$, whereas rats isolated for $24 \mathrm{~h}$ showed about twice as much pinning compared to those seen after $3.5 \mathrm{~h}$ of isolation. Methylphenidate $(0.3-3.0 \mathrm{mg} / \mathrm{kg}$, s.c.) suppressed pinning after both $0 \mathrm{~h}$ (Figure 1e) and $24 \mathrm{~h}$ of social isolation (Figure 1f). When the effect of methylphenidate was expressed as percentage of saline treatment, its relative effect after $0,3.5$, and $24 \mathrm{~h}$ of social isolation was highly comparable (Figure 1g). After $0 \mathrm{~h}$ of social isolation, methylphenidate (at 1.0 and $3.0 \mathrm{mg} / \mathrm{kg}$ ) also suppressed pouncing $\left(\mathrm{F}_{3,31}=4.96, p<0.01\right)$ but did not affect social exploration $\left(\mathrm{F}_{3,31}=0.63\right.$, NS), whereas after $24 \mathrm{~h}$ of social isolation, methylphenidate (at $0.3-3.0 \mathrm{mg} / \mathrm{kg}$ ) decreased pouncing $\left(\mathrm{F}_{3,31}=71.57, p<0.0001\right)$ and increased social exploration $\left(\mathrm{F}_{3,31}=16.89, p<0.0001\right)$ (data not shown). Oral administration of methylphenidate also suppressed social play behavior, since both pinning (Figure 1h) and pouncing (Figure 1i), but not social exploration $\left(\mathrm{F}_{3,29}=1.19\right.$, NS; data not shown $)$, were reduced at doses of 1.0 and $3.0 \mathrm{mg} / \mathrm{kg}$. We also investigated whether the effect of methylphenidate could be secondary to changes in locomotor activity. Methylphenidate enhanced locomotion in animals tested singly (data not shown), but not during a social encounter (no. of crossings: saline-treated: $261.4 \pm 10.6 ;$ methylphenidate $(1.0 \mathrm{mg} / \mathrm{kg}$, s.c. $)$-treated: $275.1 \pm 11.3, \quad F_{1,31}=0.83$, NS). To distinguish whether methylphenidate suppressed the initiation to play, the responsivity to play initiation, or both, we next performed an experiment in which none, one, or both members of a test pair were treated with methylphenidate $(3.0 \mathrm{mg} / \mathrm{kg}$, s.c.), and behavior of both test partners was scored separately. Consistent with the previous experiments, there was a complete suppression of pinning (Figure 2a) and pouncing (Figure $2 \mathrm{~b}$ ), but no change in social exploration (Figure 2c) when both members of a pair were treated with methylphenidate. When only one animal of a pair was treated, there was also a complete suppression of pinning: the saline-treated rats did not pin the methylphenidatetreated animals, and the methylphenidate-treated rats did not pin the saline-treated animals (Figure 2a). However, whereas the saline-treated animal still solicited play, that is, pounced upon the methylphenidate-treated rat, although less than the saline-treated animals interacting with salinetreated animals, the methylphenidate-treated animal did not pounce upon the saline-treated rat (Figure 2b). Thus, methylphenidate suppressed both the initiation to play as well as the responsivity to play initiation.

\section{The Effect of Methylphenidate on Social Play Behavior Does Not Change after Repeated Treatment}

The psychomotor stimulant and positive reinforcing effects of psychostimulant drugs become progressively enhanced after repeated treatment (Stewart and Badiani, 1993; Robinson and Becker, 1986; Vanderschuren and Kalivas, 2000). However, the effects of methylphenidate in the treatment of ADHD are usually immediate and do not change over the course of treatment (Elia et al, 1999; Solanto, 1998). We therefore investigated whether tolerance or sensitization would occur to the effect of methylphenidate on social play behavior after repeated treatment. Animals were treated with methylphenidate $(1.0 \mathrm{mg} / \mathrm{kg}$, s.c. $)$ or saline once daily for 5 consecutive days and on the sixth day tested after treatment with an effective $(1.0 \mathrm{mg} / \mathrm{kg}$, s.c. $)$ or a subeffective dose $(0.1 \mathrm{mg} / \mathrm{kg}$, s.c. $)$ of methylphenidate. Treatment with $1.0 \mathrm{mg} / \mathrm{kg}$ methylphenidate suppressed pinning (Figure 3a) and pouncing (Figure $3 \mathrm{~b}$ ) in both saline-pretreated and methylphenidate-pretreated rats, indicating that tolerance to the effect of methylphenidate had 
EFFECT OF METHYLPHENIDATE ON SOCIAL PLAY BEHAVIOR

a

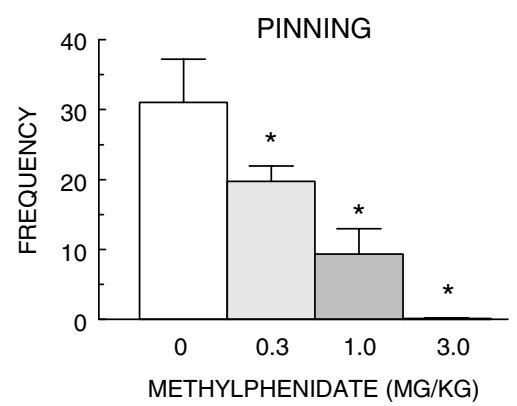

d

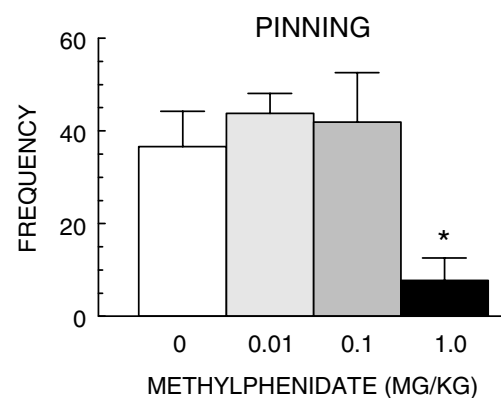

g $\quad 0-3.5-24 \mathrm{hr}$ social isolation

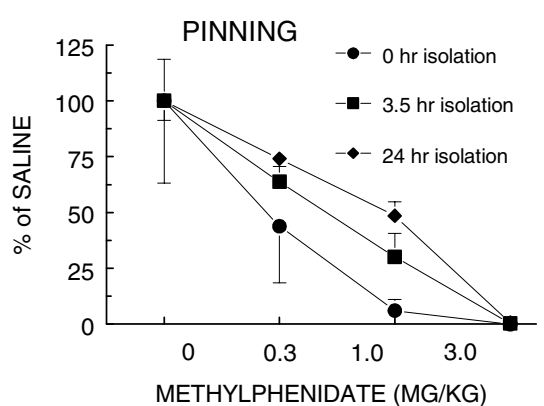

b

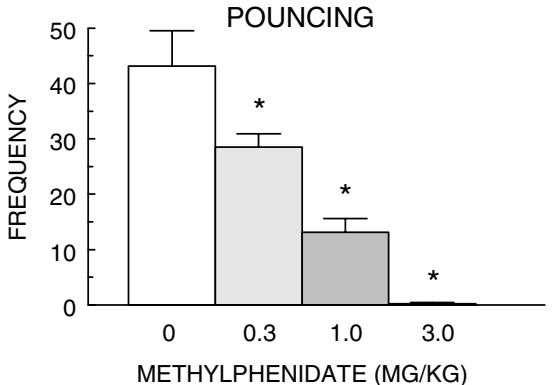

e

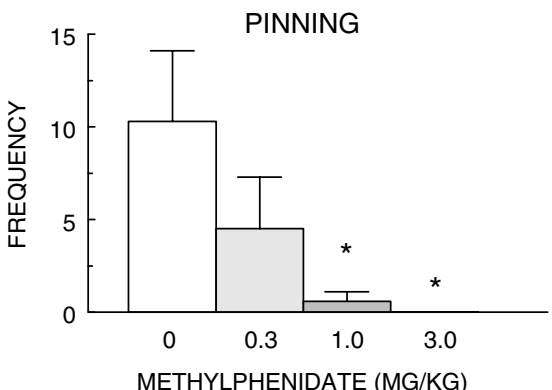

h

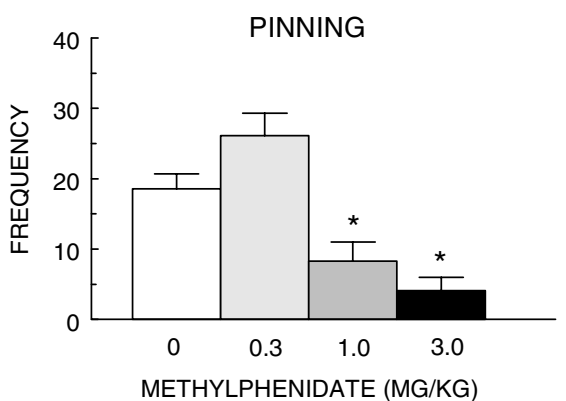

C $\quad 3.5 \mathrm{hr}$ social isolation

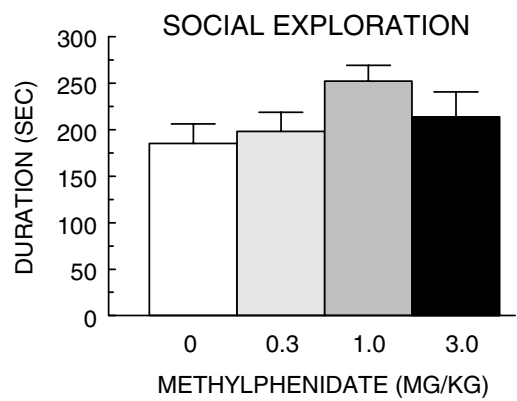

f $24 \mathrm{hr}$ social isolation

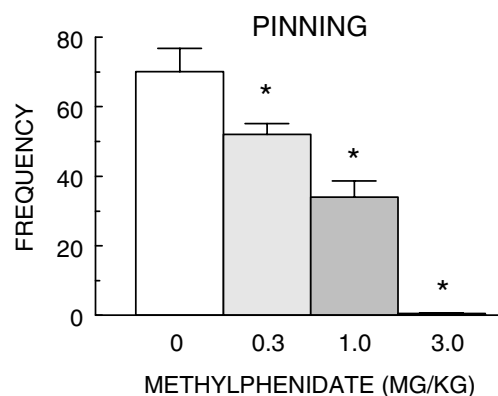

i oral administration

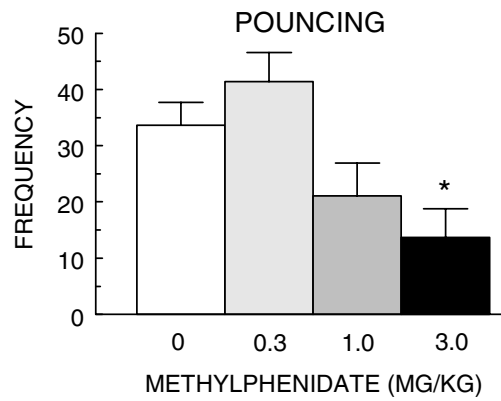

Figure I Methylphenidate $\left(0.3-3.0 \mathrm{mg} / \mathrm{kg}\right.$, s.c.) dose-dependently suppressed pinning $\left((\mathrm{a}) \mathrm{F}_{3.29}=14.96, p<0.000 \mathrm{I}\right)$ and pouncing $\left((\mathrm{b}) \mathrm{F}_{3,29}=28.90\right.$, $p<0.000 \mathrm{I}$ ) but not social exploration ( (c) $\mathrm{F}_{3,29}=\mathrm{I} .72$, NS). Lower doses of methylphenidate $(0.0 \mathrm{I}$ and $0.1 \mathrm{mg} / \mathrm{kg}$, s.c.) were ineffective in reducing pinning but $1.0 \mathrm{mg} / \mathrm{kg}$ methylphenidate, s.c., suppressed pinning ((d) $\left.F_{3,30}=5.42, p<0.0 \mathrm{I}\right)$. Methylphenidate $(0.3-3.0 \mathrm{mg} / \mathrm{kg}$, s.c.) also dose-dependently suppressed pinning in animals showing a minimal induction of social play by $0 \mathrm{~h}$ of social isolation $\left((\mathrm{e}) \mathrm{F}_{3,31}=4.18, p<0.05\right)$, or maximal induction of social play by $24 \mathrm{~h}$ of social isolation prior to the experiment $\left((\mathrm{f}) \mathrm{F}_{3,3 \mathrm{I}}=53.5 \mathrm{I}, \mathrm{p}<0.000 \mathrm{I}\right)$. The potency and efficacy of methylphenidate to suppress pinning were comparable in animals isolated for $0,3.5$, or $24 \mathrm{~h}(\mathrm{~g})$. Oral administration of methylphenidate also suppressed pinning $\left((\mathrm{h}) \mathrm{F}_{3,29}=17.50, p<0.000 \mathrm{I}\right)$ and pouncing ( (i) $F_{3,29}=6.96, p=0.00 \mathrm{l}$ ) at doses comparable to those effective after s.c. administration of methylphenidate. $(a-i) 0 \mathrm{mg} / \mathrm{kg}$ methylphenidate $=$ saline vehicle. *Significantly different from saline, $p<0.05$ (Student-Newman-Keuls test).

not occurred. Social exploration was not affected by methylphenidate pretreatment or treatment $(\mathrm{F} \text { (pretreatment })_{1,31}=0.00, \mathrm{NS} ; \mathrm{F}$ (treatment $)_{1,31}=0.03, \mathrm{NS}$; $\mathrm{F}$ (interaction $)_{1,31}=0.77$, NS; data not shown). Treatment with a low dose of methylphenidate that we previously found was subeffective in methylphenidate-naive rats (see Figure 1d) affected neither pinning (Figure 3c), pouncing (Figure 3d), nor social exploration $(\mathrm{F} \text { (pretreatment })_{1,31}=0.25, \mathrm{NS} ; \mathrm{F}$ (treatment $)_{1,31}=1.08, \mathrm{NS}$; $\mathrm{F}$ (interaction) $)_{1,31}=0.05$, NS; data not shown), in saline- or methylphenidate-pretreated rats. Thus, sensitization of this effect of methylphenidate did not occur either.

\section{Methylphenidate Suppresses Social Play through $\alpha-2$ Adrenoceptors}

The behavioral and cognitive effects of methylphenidate are usually ascribed to its impact on dopaminergic neurotransmission. However, it also targets noradrenergic neurotransmission, and there is accumulating evidence to show that this property of methylphenidate substantially contributes to its effects in ADHD (Biederman and Spencer, 1999; Bymaster et al, 2002; Arnsten and Dudley, 2005; Fone and Nutt, 2005; Berridge et al, 2006). We therefore performed a pharmacological characterization of the effects 
NONE, ONE OR BOTH ANIMALS TREATED WITH METHYLPHENIDATE

ANIMALS SCORED SEPARATELY
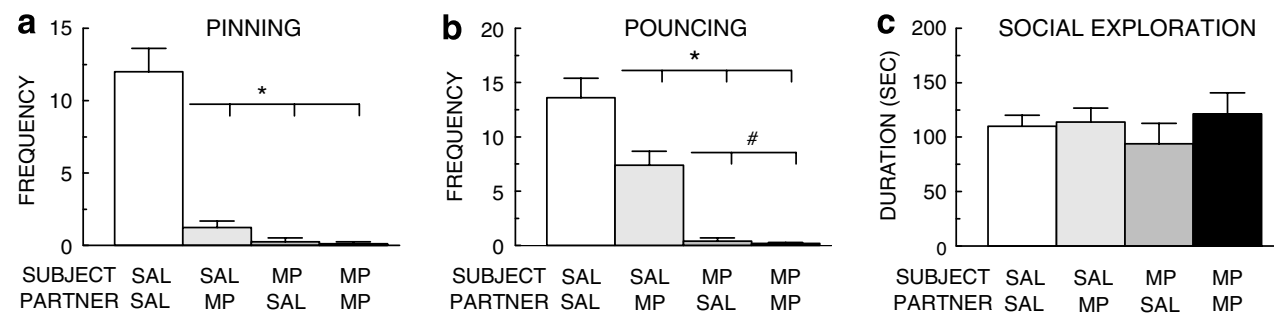

Figure 2 Assessment of social play behavior when animals in a test pair received either methylphenidate (MP; $3.0 \mathrm{mg} / \mathrm{kg}$, s.c.) or saline (SAL). 'Subject' represents the treatment of the animal whose behavior was scored; 'partner' represents the treatment of its test partner. When either one or both animals in a pair were treated with methylphenidate, pinning was completely suppressed ((a) F(treatment subject) $1.47=32.06, p<0.000$ I; $F($ treatment partner) $\left.\right|_{1,47}=22.87, p<0.000 \mathrm{I} ; \mathrm{F}$ (treatment subject $\times$ treatment partner) $\left.\right|_{1,47}=21.83, p<0.000 \mathrm{I}$ ), whereas pouncing was attenuated in saline-treated animals interacting with methylphenidate-treated animals, and completely suppressed in methylphenidate-treated animals ((b) $F($ treatment

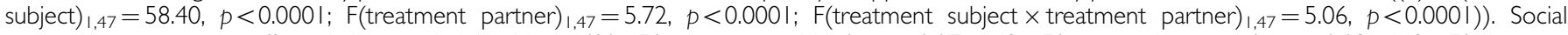
exploration was not affected by methylphenidate ((c) $F$ (treatment subject) $)_{1,47}=0.07$, NS; $F$ (treatment partner) $)_{, 47}=0.83$, NS; $F($ treatment subject $\times$ treatment partner) $\left.)_{1,47}=0.47, \mathrm{NS}\right)$. * Significantly different from saline-treated rats interacting with saline-treated rats $(\mathrm{SAL} / \mathrm{SAL}), p<0.05$ (Student-Newman-Keuls test); ${ }^{\#}$ significantly different from saline-treated rats interacting with methylphenidate-treated rats (SAL/MP), $p<0.05$ (StudentNewman-Keuls test).

\section{METHYLPHENIDATE PRETREATMENT \\ TEST WITH EFFECTIVE METHYLPHENIDATE DOSE}
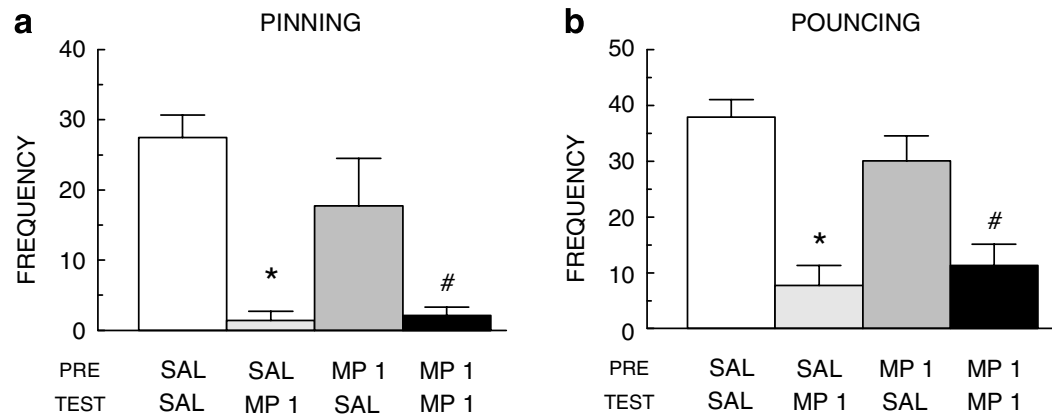

METHYLPHENIDATE PRETREATMENT

TEST WITH SUBEFFECTIVE METHYLPHENIDATE DOSE
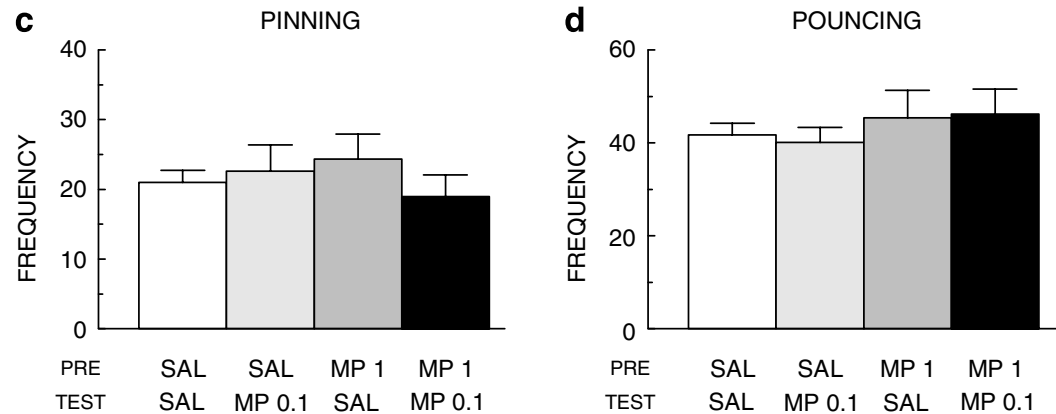

Figure 3 Pretreatment (PRE) with methylphenidate (MP I; $1.0 \mathrm{mg} / \mathrm{kg}$, s.c., once daily for 5 consecutive days) did not alter the effectiveness of methylphenidate (TEST) to suppress social play. (a) Effect of $1.0 \mathrm{mg} / \mathrm{kg}$ methylphenidate, s.c. (MP I), or saline (SAL) on pinning after 5 days of pretreatment

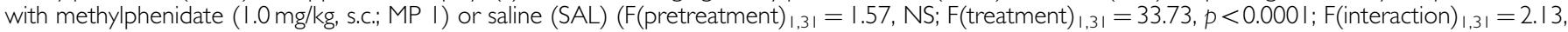
$\mathrm{NS}$ ). (b) Effect of $1.0 \mathrm{mg} / \mathrm{kg}$ methylphenidate, s.c. (MP I), or saline (SAL) on pouncing after 5 days of pretreatment with methylphenidate (I.0 mg/kg, s.c.; $M P$ I)

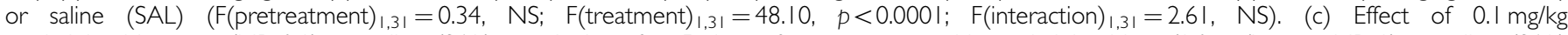
methylphenidate, s.c. (MP 0.I), or saline (SAL) on pinning after 5 days of pretreatment with methylphenidate $(\mathrm{I} .0 \mathrm{mg} / \mathrm{kg}, \mathrm{s.c}$; $\mathrm{MP}$ I) or saline (SAL) $\left(F(\text { pretreatment })_{|, 3|}=0.002 \text {, NS; F(treatment) }\right)_{1,3 \mid}=0.4 I$, NS; F(interaction) $)_{1,3 \mid}=1.43$, NS). (d) Effect of 0.1 mg $/ \mathrm{kg}$ methylphenidate, s.c. (MP 0. I), or saline $(\mathrm{SAL})$ on pouncing after 5 days of pretreatment with methylphenidate $(1.0 \mathrm{mg} / \mathrm{kg}$, s.c.; $\mathrm{MP} \quad \mathrm{I})$ or saline $(\mathrm{SAL})(\mathrm{F}(\mathrm{pretreatment})|.3|=\mid .36$, $\mathrm{NS}$;

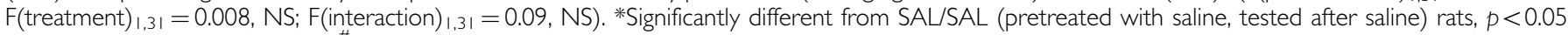
(Student-Newman-Keuls test); ${ }^{\#}$ significantly different from MP I/SAL (pretreated with methylphenidate, tested after saline) rats, $p<0.05$ (StudentNewman-Keuls test). 

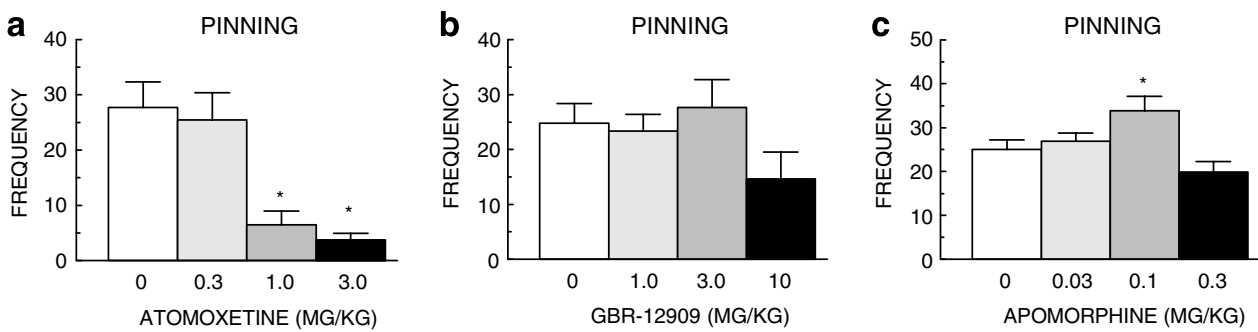

Figure 4 The selective noradrenaline reuptake inhibitor atomoxetine ((a) $0.3-3.0 \mathrm{mg} / \mathrm{kg}$, i.p.; $F_{3,31}=\mid$ I.9l, $p<0.000$ I), but not the selective dopamine reuptake inhibitor GBR-I2909 ((b) I.0-10 mg/kg, s.c.; $F_{3,32}=1.71$, NS), dose-dependently suppressed pinning. The dopamine receptor agonist apomorphine slightly increased pinning ((c) $0.03-0.3 \mathrm{mg} / \mathrm{kg}$, s.c.; $F_{3,31}=5.44, p<0.01$ ). (a-c) $0 \mathrm{mg} / \mathrm{kg}=$ saline vehicle. *Significantly different from saline, $p<0.05$ (StudentNewman-Keuls test)

of methylphenidate on social play. The noradrenaline reuptake inhibitor atomoxetine $\left(\right.$ Strattera $\left.{ }^{\mathbb{R}}\right)$, which is also used in the treatment of ADHD (Spencer et al, 2002; Michelson et al, 2003; Kratochvil et al, 2006), suppressed pinning (Figure 4a). However, neither the dopamine reuptake inhibitor GBR-12909 (Figure 4b) nor the dopamine receptor agonist apomorphine (Figure 4c) inhibited social play. In fact, apomorphine stimulated pinning at one dose. We next tried to clarify through which noradrenergic receptor methylphenidate exerts its effects, using the $\alpha-2$ adrenoceptor antagonist RX821002, the $\alpha-1$ adrenoceptor antagonist prazosin, the $\beta$-adrenoceptor antagonist propranolol, as well as the dopamine receptor antagonist cis-(Z)flupenthixol. Since some of these drugs have previously been shown to affect social play themselves (Beatty et al, 1984; Siviy et al, 1994), we first performed pilot studies and used doses of these drugs that had no effect on social play by themselves. Pretreatment with the $\alpha-2$ adrenoceptor antagonist RX821002 prevented the effect of methylphenidate on pinning (Figure 5a). However, neither prazosin (Figure 5b), propranolol (Figure 5c), nor cis-(Z)-flupenthixol (Figure 5d) influenced the effect of methylphenidate. RX821002 also blocked the suppressant effect on pinning of atomoxetine (Figure 5e). Combined treatment with subeffective doses of methylphenidate $(0.1 \mathrm{mg} / \mathrm{kg})$ and atomoxetine $(0.3 \mathrm{mg} / \mathrm{kg})$ also suppressed pinning (Figure $5 \mathrm{f})$. The pattern of effects on pouncing paralleled that seen for pinning, that is, suppression by methylphenidate and atomoxetine, which was blocked by RX821002 but not prazosin, propranolol, or cis-(Z)-flupenthixol. Moreover, combined treatment with subeffective doses of methylphenidate and atomoxetine also suppressed pouncing. There were no major drug effects on social exploration (data not shown).

\section{DISCUSSION}

The present data show that low doses of methylphenidate block social play behavior in adolescent rats. This effect was behaviorally specific: methylphenidate did not alter social exploratory behavior or locomotor activity during social interaction, demonstrating that changes in general sociability or locomotion did not underlie the effects of methylphenidate on social play. Moreover, the effect of methylphenidate was not dependent on the baseline level of social play behavior, because it was equally potent in animals isolated for $0,3.5$, and $24 \mathrm{~h}$, which displayed levels of social play that differed approximately sixfold. An experiment in which only one animal in a test pair was treated showed that methylphenidate blocked the initiation to play, as well as the responsiveness to play initiation. The effect of methylphenidate on social play behavior was not subject to tolerance or sensitization. In addition, the playsuppressant effect of methylphenidate was mediated by a noradrenergic mechanism: it was mimicked by the noradrenaline reuptake inhibitor atomoxetine, which is also used for the treatment of ADHD, but not by the dopamine reuptake blocker GBR-12909 or the dopamine receptor agonist apomorphine. The effects of methylphenidate and atomoxetine were blocked by pretreatment with the $\alpha-2$ adrenoceptor antagonist RX821002, but the effect of methylphenidate was not altered by the dopamine receptor antagonist cis-(Z)-flupenthixol, the $\alpha-1$ adrenoceptor antagonist prazosin, or the $\beta$-adrenoceptor antagonist propranolol. In addition, combined administration of subeffective doses of methylphenidate and atomoxetine suppressed social play. Together, these data show that methylphenidate, at doses comparable to those used for the treatment of ADHD, potently suppresses the most vigorous part of the behavioral repertoire of adolescent rats through stimulation of $\alpha-2$ adrenoceptors.

There are striking parallels between the effect of methylphenidate described here and its therapeutic properties in ADHD. The effect of methylphenidate on social play behavior was immediate and not subject to tolerance or sensitization, which is also the case for its effects in ADHD (Elia et al, 1999; Solanto, 2000). In addition, methylphenidate suppressed social play after both subcutaneous and oral administration. This is important, because there is discussion about whether the effects of methylphenidate found in rodents can be translated to the human situation. There is a strong variation in bioavailability of the drug after different routes of administration, and methylphenidate doses that are used in rodents (often $5 \mathrm{mg} / \mathrm{kg}$ and higher) have behavioral and neurochemical consequences that can be very different to the low doses of the drug (typically in the range of $0.3-3.0 \mathrm{mg} / \mathrm{kg}$ ) that are orally effective in humans (Gerasimov et al, 2000; Kuczenski and Segal, 2002; Arnsten and Dudley, 2005; Berridge et al, 2006). 
EFFECTS OF NORADRENALINE AND DOPAMINE RECEPTOR ANTAGONISTS

ON THE EFFECTS OF METHYLPHENIDATE AND ATOMOXETINE ON SOCIAL PLAY BEHAVIOR
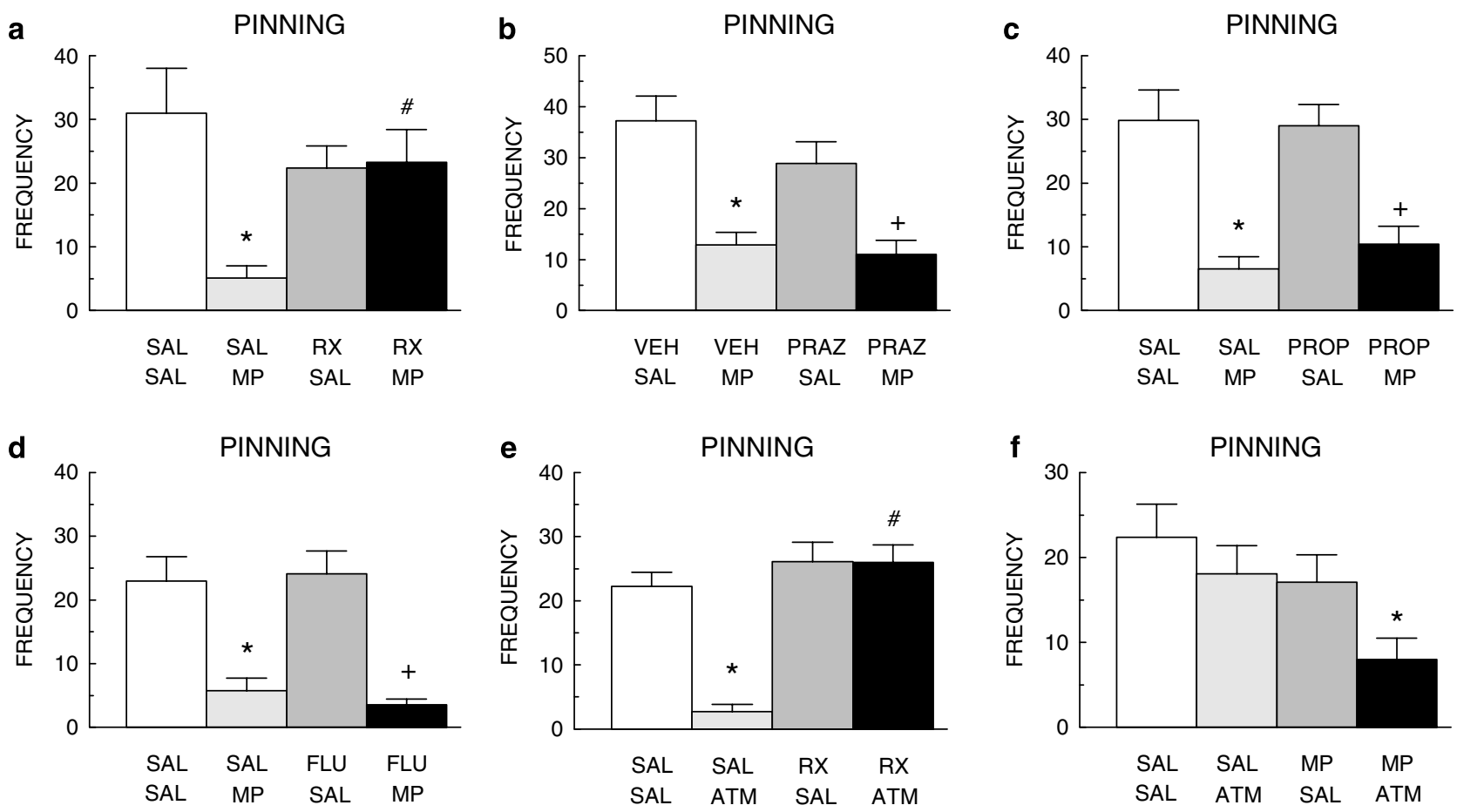

Figure 5 The effect of methylphenidate (MP; $1.0 \mathrm{mg} / \mathrm{kg}$, s.c.) on pinning was blocked by the $\alpha$-2 adrenoceptor antagonist $R \times 821002$ (RX; $0.2 \mathrm{mg} / \mathrm{kg}$, i.p.)

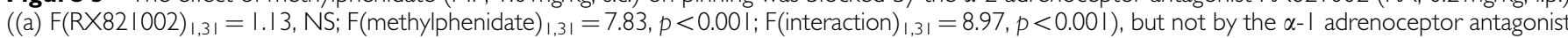

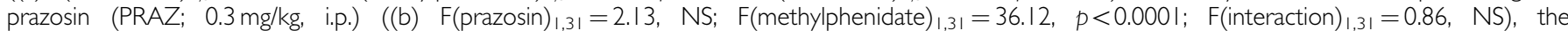
$\beta$-adrenoceptor antagonist propranolol (PROP; $3.0 \mathrm{mg} / \mathrm{kg}$, i.p.) ((c) $\mathrm{F}$ (propranolol) $3,27=0.23, \mathrm{NS} ; \mathrm{F}$ (methylphenidate) $)_{3,27}=44.97, p<0.000 \mathrm{I} ; \mathrm{F}$ (interaction $)_{3,27}=0.57$, NS), or the dopamine receptor antagonist cis-(Z)-flupenthixol (FLU; $0.125 \mathrm{mg} / \mathrm{kg}$, i.p.) $((\mathrm{d}) \quad \mathrm{F}($ cis-(Z)-flupenthixol)।,30 $=0.04$, NS; $F\left(\right.$ methylphenidate) ${ }_{1,30}=47.58, p<0.000$ ।; F(interaction) $1,30=0.36$, NS). RX82 1002 (RX; $0.2 \mathrm{mg} / \mathrm{kg}$, i.p.) also blocked the effect of atomoxetine (ATM; $1.0 \mathrm{mg} / \mathrm{kg}$, i.p.) on pinning ((e) $F(R \times 821002)_{1,30}=35.16, p<0.000 I_{;} F(\text { atomoxetine })_{1,30}=18.43, p<0.000 I_{;} F(\text { interaction })_{1,30}=|7.96, p<0.000|$ ). Combined treatment with subeffective doses of methylphenidate (MP; $0.1 \mathrm{mg} / \mathrm{kg}$, s.c.) and atomoxetine (ATM; $0.3 \mathrm{mg} / \mathrm{kg}$, i.p.) suppressed pinning $((f) \quad F \text { (methylphenidate) })_{1,63}=5.94, \quad p<0.05 ; \quad F$ (atomoxetine) $)_{1,63}=4.58, \quad p<0.05 ; \quad F$ (interaction) $\left.)_{1,63}=0.58, \quad N S\right) . \quad S A L=$ saline; $\quad V E H=v e h i c l e$ (distilled water). *Significantly different from SALSAL (a, c-f) or VEH/SAL (b), $p<0.05$ (Student-Newman-Keuls test); ${ }^{*}$ significantly different from SAL/ MP (a) or SAL/ATM (e), $p<0.05$ (Student-Newman-Keuls test); ${ }^{+}$significantly different from PRAZ/SAL (b), PROP/SAL (c), or FLU/SAL (d), p<0.05 (Student-Newman-Keuls test).

In the present study, we chose to administer methylphenidate subcutaneously, which results in a slower rate of absorption and lower peak levels of drug than intraperitoneal administration (Benet et al, 1996). We also verified that the effect of methylphenidate after subcutaneous administration was similar to that after oral administration. In fact, the effective oral doses of methylphenidate $(1.0-3.0 \mathrm{mg} / \mathrm{kg})$ are within the range used in humans (Elia et al, 1999; Kutcher et al, 2004).

It is now widely accepted that the effects of psychostimulant drugs in ADHD are not paradoxical or specific to humans. The reduction of hyperactivity induced by psychostimulants is observed in both ADHD patients and normal children (Rapoport et al, 1978, 1980), the cognitive effects of methylphenidate in normal subjects and ADHD patients are also similar (Tannock et al, 1989; Elliott et al, 1997; Solanto et al, 1997; Mehta et al, 2000, 2004; Aron et al, 2003; Hawk et al, 2003; Overtoom et al, 2003; Pietras et al, 2003; Volkow et al, 2004), and comparable cognitive effects have also been found in rodents (Arnsten and Dudley, 2005; Berridge et al, 2006; van Gaalen et al, 2006; Bizot et al, 2007;
Eagle et al, 2007). Together, this indicates that testing the behavioral effects of low doses of psychostimulant drugs in rodents yields information that is relevant for humans, and can help understand their mechanism of action in ADHD.

The effect of methylphenidate on social play behavior is therefore likely related to its therapeutic effects in ADHD, so that the investigation of its neurobehavioral underpinnings may yield information about the mechanism of action of methylphenidate. Of course, our data do not indicate that any drug-induced reduction in social play by itself reflects a therapeutic effect in ADHD. There are many neural and behavioral mechanisms by which drug treatments alter social interaction, and there is a wide variety of drugs that can modulate social play, but not all of them are active in ADHD (Vanderschuren et al, 1997; Siviy, 1998). However, on the basis of our behavioral and pharmacological analysis of the effect of methylphenidate on social play behavior, we suggest that this effect is a reflection of part of its therapeutic effect in ADHD.

The effects of psychostimulant drugs on behavior have been suggested to be rate-dependent, that is, psychostimulants 
invigorate behavior when activity levels are low, yet have suppressant effects when the intensity of behavior is high (Dews, 1958; Robbins and Sahakian, 1979). However, the finding that methylphenidate was just as potent in suppressing social play in animals showing minimal (after $0 \mathrm{~h}$ of social isolation), moderate (after $3.5 \mathrm{~h}$ of social isolation), or high levels of social play (after $24 \mathrm{~h}$ of social isolation) is inconsistent with this notion. It is also hard to reconcile the present findings with the view that psychostimulants enhance the ability of salient environmental stimuli to direct behavior (Robbins et al, 1983; Wyvell and Berridge, 2000). For a socially isolated animal, a conspecific is probably the most salient stimulus, and in this case one would expect that methylphenidate increases, rather than suppresses, social play. Moreover, this behavioral effect of psychostimulant drugs is mediated by dopaminergic neurotransmission (Wolterink et al, 1993), whereas the effect on social play behavior is not. Given that the effect of methylphenidate on social play is mediated by a noradrenergic mechanism, this effect could be related to the function of increases in tonic noradrenergic neurotransmission, that is, disengagement of a current task and search for alternative behaviors, which can become apparent as increased distractibility or response switching (Aston-Jones and Cohen, 2005). Quite clearly, however, increased distractibility or response switching would indicate that these low doses of methylphenidate would worsen, rather than ameliorate, ADHD symptoms. Therefore, we think that a more likely explanation for the effect of methylphenidate on social play lies in the observations that methylphenidate improves behavioral inhibition, as measured using a stopsignal reaction time task in rats (Eagle et al, 2007) and humans (Tannock et al, 1989; Aron et al, 2003). This effect on behavioral inhibition may be related to the notion that psychostimulant drugs cut short complex chains of behavior, such as social interactions (Lyon and Robbins, 1975). Interestingly, the pharmacological profile of the effects of psychostimulants in the stop-signal reaction time task is very similar to the effects found here on social play, because the effect of methylphenidate on stop task performance was not blocked by cis-(Z)-flupenthixol (Eagle et al, 2007) and mimicked by atomoxetine (Chamberlain et al, 2006; Robinson et al, 2007). Together, these findings suggest that the effects of methylphenidate on social play behavior are the result of increased behavioral inhibition, suppressing vigorous forms of behavior that are likely associated with diminished attention for the environment (Vanderschuren et al, 1997; Špinka et al, 2001). Increased behavioral inhibition also implies that the effect of methylphenidate would not be remediated by the presence of an untreated rat. Indeed, our observation that both the initiation to play as well as the responsivity to play initiation is reduced by methylphenidate is consistent with this notion.

Pharmacological analysis showed that the effects of methylphenidate and atomoxetine on social play were mediated through $\alpha-2$ adrenoceptors. At first glance, this may seem counterintuitive, as $\alpha-2$ adrenoceptors are usually thought to act as presynaptic autoreceptors (Starke et al, 1989). Blocking these receptors would then enhance, rather than inhibit, the effects of methylphenidate and atomoxetine. However, $\alpha-2$ adrenoceptors are also located postsynaptically, and there is substantial evidence that stimulation of postsynaptic $\alpha-2$ adrenoceptors can improve prefrontal cognitive functions, such as working memory and behavioral inhibition (Aron et al, 2004; Arnsten and Dudley, 2005; Arnsten, 2006). The notion that methylphenidate and atomoxetine suppress social play through a similar mechanism was further supported by the observation that combined treatment with subeffective doses of these drugs reduced play. Our data, showing that the effect of methylphenidate on social play behavior is mediated by a noradrenergic mechanism but is independent of dopaminergic neurotransmission, add to the evidence that methylphenidate has dissociable effects on behavior through both dopaminergic and noradrenergic mechanisms. For example, the effects of methylphenidate on impulsive choice are mediated by both dopaminergic and noradrenergic neurotransmission (Van Gaalen et al, 2006; Robinson et al, 2007), whereas the effects of this drug on stop-signal reaction time task performance (Chamberlain et al, 2006; Eagle et al, 2007; Robinson et al, 2007) and social play (present study) are mediated by a noradrenergic mechanism.

Social play behavior is a natural reinforcer (Humphreys and Einon, 1981; Normansell and Panksepp, 1990; Calcagnetti and Schechter, 1992; Crowder and Hutto, 1992; Van den Berg et al, 1999b), so it may come as a surprise that stimulating dopaminergic neurotransmission with the dopamine receptor agonist apomorphine and the dopamine reuptake blocker GBR-12909 has no major effects on social play (see also Niesink and Van Ree, 1989; Siviy et al, 1996). Dopaminergic neurotransmission plays a critical role in the incentive-motivational, but not the hedonic, pleasurable properties of drugs of abuse and natural rewards (Cardinal et al, 2002; Schultz, 2002; Wise, 2004; Berridge, 2007; Salamone et al, 2007). Our experimental setup, however, is such that incentive-motivational and pleasurable properties of social play cannot readily be distinguished. Perhaps the latter play a more prominent role in the observed behavior, because the presentation of a gregarious conspecific after a short period of social isolation may be pleasurable in itself, so heightened motivation has no major effects on social play. Our findings are reminiscent of the extensive literature on feeding, which shows that in a free-feeding situation, changes in dopamine neurotransmission do not alter food intake (even though changes in the motivation for food could in theory alter feeding), but in an operant setting, changes in dopaminergic neurotransmission determine whether food is perceived as attractive and how much effort the animal is willing to exert to obtain it (for reviews see Baldo and Kelley, 2007; Barbano and Cador, 2007; Berridge, 2007; Salamone et al, 2007).

In summary, our data show that methylphenidate suppresses vigorous social behavior through stimulation of $\alpha-2$ adrenoceptors, probably by enhancing behavioral inhibition. However, even though we think that this effect of methylphenidate reflects its therapeutic properties in ADHD, the observation that this drug so powerfully suppresses social play also warrants caution. Social play behavior subserves social and cognitive development, and constitutive suppression of this behavior may lead to longlasting behavioral deficits (Hol et al, 1999; Van den Berg et al, 1999a; Špinka et al, 2001). Even though the few 
available studies show that repeated methylphenidate treatment does not cause residual changes in social interaction (Sproson et al, 2001; Bolaños et al, 2003), there is increasing evidence that repeated treatment with low doses of methylphenidate can have long-lasting effects on behavior (Brandon et al, 2001; Andersen et al, 2002; Bolaños et al, 2003; Carlezon and Konradi, 2004). Thus, further research into the persistent behavioral effects of chronic exposure to low doses of methylphenidate is warranted.

\section{ACKNOWLEDGEMENTS}

This work was supported by National Institute on Drug Abuse Grant R01 DA022628 (LJMJV). We thank Professor W Matthys and Professor JM Van Ree for thoughtful comments on a draft version of this manuscript and $\mathrm{MH}$ Broekhoven and R Damsteegt for practical assistance. V Trezza was a visiting scientist from the Department of Human Physiology and Pharmacology, University of Rome 'Sapienza,' Rome, Italy, supported by a fellowship from the Italian Ministry of Scientific Research.

\section{DISCLOSURE/CONFLICT OF INTEREST}

The authors declare that, except for income received from their primary employers, no financial support or compensation has been received from any individual or corporate entity over the past 3 years for research or professional service and there are no personal financial holdings that could be perceived as constituting a potential conflict of interest.

\section{REFERENCES}

American Psychiatric Association (2000). Diagnostic and Statistical Manual of Mental Disorders, IV-TR edn. American Psychiatric Association: Washington, DC.

Andersen SL, Arvanitogiannis A, Pliakas AM, LeBlanc C, Carlezon Jr WA (2002). Altered responsiveness to cocaine in rats exposed to methylphenidate during development. Nat Neurosci 5: 13-14.

Arakawa O (1994). Effects of methamphetamine and methylphenidate on single and paired rat open-field behaviors. Physiol Behav 55: 441-446.

Arnsten AFT (2006). Stimulants: therapeutic actions in ADHD. Neuropsychopharmacology 31: 2376-2383.

Arnsten AFT, Dudley AG (2005). Methylphenidate improves prefrontal cortical cognitive function through $\alpha 2$ adrenoceptor and dopamine D1 receptor actions: relevance to therapeutic effects in attention deficit hyperactivity disorder. Behav Brain Funct 1: 2.

Aron AR, Dowson JH, Sahakian BJ, Robbins TW (2003). Methylphenidate improves response inhibition in adults with attentiondeficit/hyperactivity disorder. Biol Psychiatry 54: 1465-1468.

Aron AR, Robbins TW, Poldrack RA (2004). Inhibition and the right inferior frontal cortex. Trends Cogn Sci 8: 170-177.

Aston-Jones G, Cohen JD (2005). An integrative theory of locus coeruleus-norepinephrine function: adaptive gain and optimal performance. Annu Rev Neurosci 28: 403-450.

Baldo BA, Kelley AE (2007). Discrete neurochemical coding of distinguishable motivational processes: insights from nucleus accumbens control of feeding. Psychopharmacology 191: 439-459.
Barbano MF, Cador M (2007). Opioids for hedonic experience and dopamine to get ready for it. Psychopharmacology 191: 497-506.

Beatty WW, Costello KB, Berry SL (1984). Suppression of play fighting by amphetamine: effects of catecholamine antagonists, agonists and synthesis inhibitors. Pharmacol Biochem Behav 20: 747-755.

Beatty WW, Dodge AM, Dodge LJ, Panksepp J (1982). Psychomotor stimulants, social deprivation and play in juvenile rats. Pharmacol Biochem Behav 16: 417-422.

Benet LZ, Kroetz DL, Sheiner LB (1996). The dynamics of drug absorption, distribution, and elimination. In: Hardman JG, Limbird LE, Molinoff PB, Ruddon RW, Goodman Gilman A (eds). Goodman \& Gilman's The Pharmacological Basis of Therapeutics. McGraw-Hill: New York. pp 3-27.

Berridge CW, Devilbiss DM, Andrzejewski ME, Arnsten AFT, Kelley AE, Schmeichel B et al (2006). Methylphenidate preferentially increases catecholamine neurotransmission within the prefrontal cortex at low doses that enhance cognitive function. Biol Psychiatry 60: 1111-1120.

Berridge KC (2007). The debate over dopamine's role in reward: the case for incentive salience. Psychopharmacology 191: 391-431.

Biederman J, Faraone SV (2005). Attention-deficit hyperactivity disorder. Lancet 366: 237-248.

Biederman J, Spencer T (1999). Attention-deficit/hyperactivity disorder (ADHD) as a noradrenergic disorder. Biol Psychiatry 46: 1234-1242.

Bizot J-C, Chenault N, Houzé B, Herpin A, David S, Pothion S et al (2007). Methylphenidate reduces impulsive behaviour in juvenile Wistar rats, but not in adult Wistar, SHR and WKY rats. Psychopharmacology 193: 215-223.

Bolaños CA, Barrot M, Berton O, Wallace-Black D, Nestler EJ (2003). Methylphenidate treatment during pre- and periadolescence alters behavioral responses to emotional stimuli at adulthood. Biol Psychiatry 54: 1317-1329.

Brandon CL, Marinelli M, Baker LK, White FJ (2001). Enhanced reactivity and vulnerability to cocaine following methylphenidate treatment in adolescent rats. Neuropsychopharmacology 25: 651-661.

Bymaster FP, Katner JS, Nelson DL, Hemrick-Luecke SK, Threlkeld PG, Heiligenstein JH et al (2002). Atomoxetine increases extracellular levels of norepinephrine and dopamine in prefrontal cortex of rat: a potential mechanism for efficacy in attention deficit/hyperactivity disorder. Neuropsychopharmacology 27: 699-711.

Calcagnetti DJ, Schechter MD (1992). Place conditioning reveals the rewarding aspect of social interaction in juvenile rats. Physiol Behav 51: 667-672.

Cardinal RN, Parkinson JA, Hall J, Everitt BJ (2002). Emotion and motivation: the role of the amygdala, ventral striatum, and prefrontal cortex. Neurosci Biobehav Rev 26: 321-352.

Carlezon Jr WA, Konradi C (2004). Understanding the neurobiological consequences of early exposure to psychotropic drugs: linking behavior with molecules. Neuropharmacology 47(Suppl 1): 47-60.

Chacko A, Pelham WE, Gnagy EM, Greiner A, Vallano G, Bukstein O et al (2005). Stimulant medication effects in a summer treatment program among young children with attention-deficit/ hyperactivity disorder. J Am Acad Child Adolesc Psychiatry 44: 249-257.

Chamberlain SR, Müller U, Blackwell AD, Clark L, Robbins TW, Sahakian BJ (2006). Neurochemical modulation of response inhibition and probabilistic learning in humans. Science 311: 861-863.

Connor DF, Glatt SJ, Lopez ID, Jackson D, Melloni Jr RH (2002). Psychopharmacology and aggression. I: A meta-analysis of stimulant effects on overt/covert aggression-related behaviors in ADHD. J Am Acad Child Adolesc Psychiatry 41: 253-261. 
Crowder WF, Hutto Jr CW (1992). Operant place conditioning measures examined using two nondrug reinforcers. Pharmacol Biochem Behav 41: 817-824.

Dews PB (1958). Studies on behavior. IV. Stimulant actions of methamphetamine. J Pharmacol Exp Ther 122: 137-147.

Eagle DM, Tufft MRA, Goodchild HL, Robbins TW (2007). Differential effects of modafinil and methylphenidate on stopsignal reaction time task performance in the rat, and interactions with the dopamine receptor antagonist cis-flupenthixol. Psychopharmacology 192: 193-206.

Elia J, Ambrosini PJ, Rapoport JL (1999). Treatment of attentiondeficit-hyperactivity disorder. $N$ Engl J Med 340: 780-788.

Elliott R, Sahakian BJ, Matthews K, Bannerjea A, Rimmer J, Robbins TW (1997). Effects of methylphenidate on spatial working memory and planning in healthy young adults. Psychopharmacology 131: 196-206.

Ferris RM, Tang FLM (1979). Comparison of the effects of the isomers of amphetamine, methylphenidate and deoxypipradrol on the uptake of $l-\left[{ }^{3} \mathrm{H}\right]$ norepinephrine and $\left[{ }^{3} \mathrm{H}\right]$ dopamine by synaptic vesicles from rat whole brain, striatum and hypothalamus. J Pharmacol Exp Ther 210: 422-428.

Fone KCF, Nutt DJ (2005). Stimulants: use and abuse in the treatment of attention deficit hyperactivity disorder. Curr Opin Pharmacol 5: 87-93.

Gerasimov MR, Franceschi M, Volkow ND, Gifford A, Gatley SJ, Marsteller D et al (2000). Comparison between intraperitoneal and oral methylphenidate administration: a microdialysis and locomotor activity study. J Pharmacol Exp Ther 295: 51-57.

Hawk Jr LW, Yartz AR, Pelham Jr WE, Lock TM (2003). The effects of methylphenidate on prepulse inhibition during attended and ignored prestimuli among boys with attention-deficit hyperactivity disorder. Psychopharmacology 165: 118-127.

Hinshaw SP, Lee SS (2000). Ritalin effects on aggression and antisocial behavior. In: Greenhill LL, Osman BB (eds). Ritalin: Theory and Practice. Mary Ann Liebert Inc. Publishers: New Rochelle. pp 237-251.

Hol T, Van den Berg C, Van Ree JM, Spruijt BM (1999). Isolation during the play period in infancy decreases adult social interactions in rats. Behav Brain Res 100: 91-97.

Humphreys AP, Einon DF (1981). Play as a reinforcer for mazelearning in juvenile rats. Anim Behav 29: 259-270.

Kratochvil CJ, Wilens TE, Greenhill LL, Gao H, Baker KD, Feldman PD et al (2006). Effects of long-term atomoxetine treatment for young children with attention-deficit/hyperactivity disorder. $J$ Am Acad Child Adolesc Psychiatry 45: 919-927.

Kuczenski R, Segal DS (2002). Exposure of adolescent rats to oral methylphenidate: preferential effects on extracellular norepinephrine and absence of sensitization and cross-sensitization to methamphetamine. J Neurosci 22: 7264-7271.

Kutcher S, Aman M, Brooks SJ, Buitelaar J, van Daalen E, Fegert J et al (2004). International consensus statement on attentiondeficit/hyperactivity disorder (ADHD) and disruptive behaviour disorders (DBDs): clinical implications and treatment practice suggestions. Eur Neuropsychopharmacol 14: 11-28.

Lyon M, Robbins TW (1975). The action of central nervous system stimulant drugs: a general theory concerning amphetamine effects. In: Essman W, Valzelli L (eds). Current Developments in Psychopharmacology. Spectrum: New York. pp 79-163.

Mehta MA, Goodyer IM, Sahakian BJ (2004). Methylphenidate improves working memory and set-shifting in AD/HD: relationships to baseline memory capacity. J Child Psychol Psychiatry 45: 293-305.

Mehta MA, Owen AM, Sahakian BJ, Mavaddat N, Pickard JD, Robbins TW (2000). Methylphenidate enhances working memory by modulating discrete frontal and parietal lobe regions in the human brain. J Neurosci 20: RC65 (1-6).

Michelson DM, Adler L, Spencer T, Reimherr FW, West SA, Allen AJ et al (2003). Atomoxetine in adults with ADHD: two randomized, placebo-controlled studies. Biol Psychiatry 53: $112-120$

Miczek KA, Haney M, Tidey J, Vatne T, Weerts E, DeBold JF (1989). Temporal and sequential patterns of agonistic behavior: effects of alcohol, anxiolytics and psychomotor stimulants. Psychopharmacology 97: 149-151.

Moro M, Salvador A, Simón VM (1997). Changes in the structure of the agonistic behavior of mice produced by D-amphetamine. Pharmacol Biochem Behav 56: 47-54.

Niesink RJM, Van Ree JM (1989). Involvement of opioid and dopaminergic systems in isolation-induced pinning and social grooming of young rats. Neuropharmacology 28: 411-418.

Normansell L, Panksepp J (1990). Effects of morphine and naloxone on play-rewarded spatial discrimination in juvenile rats. Dev Psychobiol 23: 75-83.

Overtoom CCE, Verbaten MN, Kemner C, Kenemans JL, Van Engeland H, Buitelaar JK et al (2003). Effects of methylphenidate, desipramine, and L-dopa on attention and inhibition in children with attention deficit hyperactivity disorder. Behav Brain Res 145: 7-15.

Panksepp J, Siviy SM, Normansell L (1984). The psychobiology of play: theoretical and methodological perspectives. Neurosci Biobehav Rev 8: 465-492.

Pelham Jr WE, Gnagy EM, Burrows-Maclean L, Williams A, Fabiano GA, Morrisey SM et al (2001). Once-a-day Concerta methylphenidate versus three-times-daily methylphenidate in laboratory and natural settings. Pediatrics 107: e105.

Pellis SM (1988). Agonistic versus amicable targets of attack and defense: consequences for the origin, function and descriptive classification of play-fighting. Aggress Behav 14: 85-104.

Pellis SM, Pellis VC (1987). Play-fighting differs from serious fighting in both target of attack and tactics of fighting in the laboratory rat Rattus norvegicus. Aggress Behav 13: 227-242.

Pellis SM, Pellis VC (1998). Play fighting of rats in comparative perspective: a schema for neurobehavioral analyses. Neurosci Biobehav Rev 23: 87-101.

Pietras CJ, Cherek DR, Lane SD, Tcheremissine OV, Steinberg JL (2003). Effects of methylphenidate on impulsive choice in adult humans. Psychopharmacology 170: 390-398.

Poole TB, Fish J (1975). An investigation of playful behavior in Rattus norvegicus and Mus musculus (Mammalia). J Zool Lond 175: 61-71.

Rapoport JL, Buchsbaum MS, Weingartner H, Zahn TP, Ludlow C, Mikkelsen EJ (1980). Dextroamphetamine: its cognitive and behavioral effects in normal and hyperactive boys and normal men. Arch Gen Psychiatry 37: 933-943.

Rapoport JL, Buchsbaum MS, Zahn TP, Weingartner H, Ludlow C, Mikkelsen EJ (1978). Dextroamphetamine: cognitive and behavioral effects in normal prepubertal boys. Science 199: 560-563.

Ritz MC, Lamb RJ, Goldberg SR, Kuhar MJ (1987). Cocaine receptors on dopamine transporters are related to self-administration of cocaine. Science 237: 1219-1223.

Robbins TW, Sahakian BJ (1979). 'Paradoxical' effects of psychomotor stimulant drugs in hyperactive children from the standpoint of behavioural pharmacology. Neuropharmacology 18: 931-950.

Robbins TW, Watson BA, Gaskin M, Ennis C (1983). Contrasting interactions of pipradol, $d$-amphetamine, cocaine, cocaine analogues, apomorphine and other drugs with conditioned reinforcement. Psychopharmacology 80: 113-119.

Robinson ESJ, Eagle DM, Mar AC, Bari A, Banerjee G, Jiang X et al (2007). Similar effects of the selective noradrenaline reuptake inhibitor atomoxetine on three distinct forms of impulsivity in the rat. Neuropsychopharmacology; doi: 10.1038/sj.npp.1301487.

Robinson TE, Becker JB (1986). Enduring changes in brain and behavior produced by chronic amphetamine administration: a review and evaluation of animal models of amphetamine psychosis. Brain Res Rev 11: 157-198. 
Salamone JD, Correa M, Farrar A, Mingote SM (2007). Effort-related functions of nucleus accumbens dopamine and associated forebrain circuits. Psychopharmacology 191: 461-482.

Schachter HM, Pham B, King J, Langford S, Moher D (2001). How efficacious and safe is short-acting methylphenidate for the treatment of attention-deficit disorder in children and adolescents? A meta-analysis. CMAJ 165: 1475-1488.

Schiørring E (1979). Social isolation and other behavioral changes in groups of adult vervet monkeys (Cercopithecus aethiops) produced by low, nonchronic doses of $d$-amphetamine. Psychopharmacology 64: 297-302.

Schultz W (2002). Getting formal with dopamine and reward. Neuron 36: 241-263.

Siviy SM (1998). Neurobiological substrates of play behavior: glimpses into the structure and function of mammalian playfulness. In: Bekoff M, Byers JA (eds). Animal Play. Cambridge University Press: Cambridge. pp 221-242.

Siviy SM, Fleischhauer AE, Kerrigan LA, Kuhlman SJ (1996). D2 dopamine receptor involvement in the rough-and-tumble play behavior of juvenile rats. Behav Neurosci 110: 1168-1176.

Siviy SM, Fleischhauer AE, Kuhlman SJ, Atrens DM (1994). Effects of alpha-2 adrenoceptor antagonists on rough-and-tumble play in juvenile rats: evidence for a site of action independent of nonadrenoceptor imidazoline binding sites. Psychopharmacology 113: 493-499.

Siviy SM, Panksepp J (1987). Sensory modulation of juvenile play in rats. Dev Psychobiol 20: 39-55.

Solanto MV (1998). Neuropsychopharmacological mechanisms of stimulant drug action in attention-deficit hyperactivity disorder: a review and integration. Behav Brain Res 94: 127-152.

Solanto MV (2000). Clinical psychopharmacology of AD/HD: implications for animal models. Neurosci Biobehav Rev 24: 27-30.

Solanto MV, Wender EH, Bartell SS (1997). Effects of methylphenidate and behavioral contingencies on sustained attention in attention-deficit hyperactivity disorder: a test of the reward dysfunction hypothesis. J Child Adolesc Psychopharmacol 7: 123-136.

Spencer T, Heiligenstein JH, Biederman J, Faries DE, Kratochvil CJ, Conners CK et al (2002). Results from 2 proof-of-concept, placebo-controlled studies of atomoxetine in children with attention-deficit/hyperactivity disorder. J Clin Psychiatry 63: 1140-1147.

Špinka M, Newberry RC, Bekoff M (2001). Mammalian play: training for the unexpected. Q Rev Biol 76: 141-168.

Sproson EJ, Chantrey J, Hollis C, Marsden CA, Fone KCF (2001). Effect of repeated methylphenidate administration on presynaptic dopamine and behaviour in young adult rats. J Psychopharmacol 15: 67-75.
Starke K, Göthert M, Kilbinger H (1989). Modulation of neurotransmitter release by presynaptic autoreceptors. Physiol Rev 69: 864-898.

Stewart J, Badiani A (1993). Tolerance and sensitization to the behavioral effects of drugs. Behav Pharmacol 4: 289-312.

Tannock R, Schachar RJ, Carr RP, Chajczyk D, Logan GD (1989). Effects of methylphenidate on inhibitory control in hyperactive children. J Abnorm Child Psychol 17: 473-491.

Thor DH, Holloway Jr WR (1983). Play soliciting in juvenile male rats: effects of caffeine, amphetamine and methylphenidate. Pharmacol Biochem Behav 19: 725-727.

Van den Berg CL, Hol T, Van Ree JM, Spruijt BM, Everts H, Koolhaas JM (1999a). Play is indispensable for an adequate development of coping with social challenges in the rat. Dev Psychobiol 34: 129-138.

Van den Berg CL, Pijlman FTA, Koning HAM, Diergaarde L, Van Ree JM, Spruijt BM (1999b). Isolation changes the incentive value of sucrose and social behaviour in juvenile and adult rats. Behav Brain Res 106: 133-142.

van Gaalen MM, van Koten RC, Schoffelmeer ANM, Vanderschuren LJMJ (2006). Critical involvement of dopaminergic neurotransmission in impulsive decision-making. Biol Psychiatry 60: 66-73.

Vanderschuren LJMJ, Kalivas PW (2000). Alterations in dopaminergic and glutamatergic transmission in the induction and expression of behavioral sensitization: a critical review of preclinical studies. Psychopharmacology 151: 99-120.

Vanderschuren LJMJ, Niesink RJM, Spruijt BM, Van Ree JM (1995a). Effects of morphine on different aspects of social play in juvenile rats. Psychopharmacology 117: 225-231.

Vanderschuren LJMJ, Niesink RJM, Van Ree JM (1997). The neurobiology of social play behavior in rats. Neurosci Biobehav Rev 21: 309-326.

Vanderschuren LJMJ, Spruijt BM, Hol T, Niesink RJM, Van Ree JM (1995b). Sequential analysis of social play behavior in juvenile rats: effects of morphine. Behav Brain Res 72: 89-95.

Volkow ND, Wang G-J, Fowler JS, Telang F, Maynard L, Logan J et al (2004). Evidence that methylphenidate enhances the saliency of a mathematical task by increasing dopamine in the human brain. Am J Psychiatry 161: 1173-1180.

Wise RA (2004). Dopamine, learning and motivation. Nat Rev Neurosci 5: 483-494.

Wolterink G, Phillips G, Cador M, Donselaar-Wolterink I, Robbins TW, Everitt BJ (1993). Relative roles of ventral striatal D1 and D2 dopamine receptors in responding with conditioned reinforcement. Psychopharmacology 110: 355-364.

Wyvell CL, Berridge KC (2000). Intra-accumbens amphetamine increases the conditioned incentive salience of sucrose reward: enhancement of reward 'wanting' without enhanced 'liking' or response reinforcement. J Neurosci 20: 8122-8130. 